\title{
Covid-19 is shattering US cancer care
}

American oncologists are rushing to prioritise the patients at greatest risk, institute new protections, and learn from their collective experiences, Bryn Nelson reports

\section{Bryn Nelson science journalist}

Seattle, WA, USA

\begin{abstract}
A patient in Washington, newly diagnosed with breast cancer, fought to get her lumpectomy surgery rescheduled after it was cancelled indefinitely. ${ }^{1}$ A stuffy nose required another patient in Massachusetts with a recurrent brain tumour to undergo multiple layers of screening before he could receive his immunotherapy infusion. ${ }^{2}$ A patient with bladder cancer in North Carolina couldn't get immunotherapy at all because of a lack of surgical masks and gloves. ${ }^{3}$ Then he was denied a surgical alternative because he needed a covid-19 test first. Since he hadn't been admitted to a hospital with serious covid-19 symptoms, he didn't meet the testing criteria.
\end{abstract}

Covid-19 has wreaked havoc on cancer care throughout the US as medical centres scramble to cancel or rearrange surgeries or treatments, tackle a continuing shortage of tests and supplies, and devise new safety protocols to protect a highly susceptible patient group.

"Cancer patients are the poster child for that vulnerable, high risk population," Gary Lyman, senior lead for healthcare quality and policy in the Hutchinson Institute for Cancer Outcomes Research at the Fred Hutchinson Cancer Research Center in Seattle, told The BMJ. Patients with cancer tend to be older and their compromised immunity can be further suppressed by therapeutic regimens. Preliminary reports from China and Europe, Lyman said, suggest that patients with cancer have contracted covid-19 linked respiratory disease more readily than their healthy counterparts and fared worse once infected. ${ }^{4}$

Some states-in their directives to postpone or cancel elective surgeries to reduce the risk of nosocomial infection and free up space and resources for patients with covid-19-have specifically exempted cancer surgeries. Others have not, while some have yet to give any orders. ${ }^{5}$ Justin Klamerus, president of the Karmanos Cancer Hospital and Network in hard-hit Detroit, Michigan, said his hospital is encouraging physicians to use their own judgment about whether surgeries, treatments, and other visits can be safely delayed.

Karmanos is Michigan's only dedicated cancer hospital and is receiving leukaemia patients and other urgent transfers from nearby centres that have been inundated with covid-19 cases. At the same time, the hospital has set aside a special unit to care for cancer patients infected with the coronavirus. "We don't like to say this in medicine, but we're having to learn how to manage this infection when it comes up in cancer patients, as we're managing them," Klamerus said.

\section{Hard calls and heart breaking isolation}

The pandemic is forcing some difficult choices. Sigrun Hallmeyer, medical director of the cancer service line at Advocate Lutheran General Hospital in Park Ridge, Illinois, wrestled over how to manage a patient in her 70s with locally advanced, triple negative breast cancer. Hallmeyer and the patient decided that surgery, normally the first option, would be riskier than starting with intravenous chemotherapy. Beyond the danger to her patient, Hallmeyer said using a ventilator could put others at risk. "We don't want to waste our ventilators in the operating room for elective procedures when we absolutely need them to save lives upstairs in intensive care," she told The BMJ. As of 9 April, Advocate Lutheran had 85 covid-19 inpatients; around a fourth were on respirators.

Even when doctors decide to proceed with surgery or therapy, doing so can hinge on the availability of personal protective equipment for healthcare workers and the ability to extend covid-19 testing to cancer patients who aren't hospitalised or exhibiting symptoms. "Only this week does Michigan have the capacity to test this special population even though they don't meet the criteria," Klamerus said.

The heightened safety precautions have brought new anxiety for patients like 28 year old Jeremy Pivor, who receives immunotherapy infusions at Dana-Farber Cancer Institute in Boston every three weeks to treat a brain cancer recurrence. Pivor's infusion in March was almost delayed when he had a stuffy nose, and a more recently scheduled infusion was pushed back a week when he reported feeling ill. Despite the nerve wracking uncertainty, Pivor said, "In some ways living with cancer for 16 years prepared me for the emotional challenges this pandemic has presented to society."

For others, the pandemic has exacted a heavy emotional toll. One of the cruellest aspects, Klamerus and Hallmeyer say, has been the necessary isolation of hospitalised covid-19 and cancer inpatients. One nurse recounted how, as she was transporting a covid-19 patient in crisis from a medical-surgical floor to the 
intensive care unit at Karmanos Cancer Hospital, she was the go-between for a final FaceTime call from the family. "She held the phone as the family members said, 'I love you' and some said goodbye," Klamerus said.

"What this virus has done is isolated the affected people from everything that we consider care," Hallmeyer said. "We have had our share of patients dying alone in the room without a loved one there holding their hand. It's absolutely heart breaking for me."

Amid the ongoing tragedy, oncologists say telemedicine is offering a preventive strategy to keep vulnerable cancer patients safe and could open up access to certain kinds of care like genetic counselling and long term follow-ups.

Cancer centres are also joining forces to share resources and lessons through sites like the Covid-19 and Cancer Consortium. ${ }^{6}$ Since Lyman and collaborators established the group in March, 90 North American institutions have joined. A patient registry has rapidly accumulated snapshots of "well over 300" cases from the participating centres, he said, while a more expanded version in Seattle is allowing researchers to see how patients fare over time. Klamerus said he hopes the consortium can help cancer centres learn and share information much faster than the traditional dissemination of evidence based medicine. "We can't wait that long," he said.

Competing interests: I have read and understood BMJ policy on declaration of interests and have no relevant interests to declare.

1 Stone W. Cancer patients face treatment delays and uncertainty as coronavirus cripples hospitals. Kaiser Health News. 7 April 2020. https://khn.org/news/cancer-patients-facetreatment-delays-and-uncertainty-as-coronavirus-cripples-hospitals.

2 Pivor J. Yellow tagged at my infusion: it's better to be safe than sorry. Cure. 9 April 2020 www.curetoday.com/community/jeremy-pivor/2020/04/Yellow-Tagged-at-my-Infusion--Its-Better-to-be-Safe-than-Sorry.

3 Miles M. I don't have coronavirus. It might kill me anyway. Politico. 2020. www.politico. com/news/magazine/2020/04/06/i-dont-have-coronavirus-it-might-kill-me-anyway-163101.

4 Liang W, Guan W, Chen R, et al. Cancer patients in SARS-CoV-2 infection: a nationwide analysis in China. Lancet Oncol 2020;21:335-7. 10.1016/S1470-2045(20)30096-6 32066541

5 McGuire Woods. State governors' "stay-at-home" and prohibition on elective procedures orders. 26 March 2020. www.mcguirewoods.com/client-resources/Alerts/2020/3/stategovernors-stay-at-home-prohibition-elective-procedures-orders.

6 Covid-19 and Cancer Consortium. https://ccc19.org.

Published by the BMJ Publishing Group Limited. For permission to use (where not already granted under a licence) please go to http://group.bmj.com/group/rights-licensing/ permissions 